\title{
Broadly neutralizing antibody specificities detected in the genital tract of HIV-1 infected women
}

\author{
Nonhlanhla N. Mkhize ${ }^{a, b}$, Raveshni Durgiaha ${ }^{a}$, Vicki Ashley, \\ Derseree Archary ${ }^{\text {d }}$, Nigel J. Garrett ${ }^{d}$, Quarraisha Abdool Karim ${ }^{d}$, \\ Salim S. Abdool Karim ${ }^{d}$, Penny L. Moore ${ }^{a, b, d}$, Nicole Yates ${ }^{c}$, \\ Jo-Ann S. Passmore ${ }^{d, e, f}$, Georgia D. Tomaras ${ }^{c}$ and Lynn Morris ${ }^{a, b, d}$
}

\begin{abstract}
Background: Broadly neutralizing antibodies (bNAbs) targeting conserved epitopes on the HIV envelope glycoprotein have been identified in blood from HIV-1 infected women. We investigated whether antibodies in the genital tract from these women share similar epitope specificities and functional profiles as those in blood.

Methods: Immunoglobulin (Ig)G and IgA antibodies were isolated from cervicovaginal lavages or Softcups from 13 HIV-infected women in the CAPRISA cohort using Protein $G$ and Peptide M, respectively. Binding antibodies to envelope antigens were quantified by ELISA and binding antibody multiplex assay. Neutralizing antibody titers and epitope targets were measured using the TZM-bl assay with Env-pseudotyped wild-type and mutated viruses.
\end{abstract}

Results: HIV-specific IgG, but not IgA, was detected in genital secretions and the ratio of total IgG to HIV-specific IgG was similar to plasma. HIV-specific IgG reacted with multiple envelope antigens, including V1V2, gp120, gp140 and gp41. Two women had high plasma titers of HIV-specific IgG3 which was also detected in their genital tract samples. IgG from the genital tract had neutralizing activity against both Tier 1 and Tier 2 primary HIV-isolates. Antibodies targeting well known glycan epitopes and the membrane proximal region of gp41 were detected in genital secretions, and matched specificities in plasma.

Conclusions: Women with plasma bNAbs have overlapping specificities in their genital secretions, indicating that these predominantly lgG isotype antibodies may transudate from blood to the genital tract. These data provide evidence that induction of systemic HIV-specific bNAbs can lead to antiviral immunity at the portal of entry.

Copyright (๑) 2016 Wolters Kluwer Health, Inc. All rights reserved.

AIDS 2016, 30:1005-1014

Keywords: broadly neutralizing antibodies, epitope mapping, female genital tract, HIV antibodies

\section{Introduction}

Sexual transmission of HIV remains the most common route of infection, with young women especially at risk
$[1,2]$. Mucosal surfaces of the genital tract are the principal and initial sites of infection, and therefore local mucosal antibody immunity is crucial in the control of HIV replication before systemic dissemination [3]. Broadly

\footnotetext{
${ }^{a}$ National Institute for Communicable Diseases, ${ }^{b}$ University of the Witwatersrand, Johannesburg, South Africa, ${ }^{c}$ Duke Human Vaccine Institute and Departments of Surgery, Immunology and Molecular Genetics and Microbiology, Duke University School of Medicine, Durham, North Carolina, USA, ${ }^{\mathrm{d} C e n t r e}$ for the AIDS Programme of Research in South Africa (CAPRISA), University of KwaZulu-Natal, Durban, ${ }^{\mathrm{e}}$ University of Cape Town, Cape Town, and ${ }^{\mathrm{f}}$ National Health Laboratory Services, Johannesburg, South Africa.
}

Correspondence to Lynn Morris, National Institute for Communicable Diseases, Private Bag X4, Sandringham 2131, Johannesburg, South Africa.

Tel: +27 11386 6332; fax: +27 11386 6453; e-mail: lynnm@nicd.ac.za

Received: 16 November 2015; revised: 12 January 2016; accepted: 25 January 2016. 
neutralizing antibodies (bNAbs) are able to inhibit the majority of HIV strains and, if elicited by an HIV vaccine, are likely to be effective at blocking infection at the site of entry. In non-human primates, passively infused bNAbs have been shown to inhibit simian-human immunodeficiency virus infection using the high-dose vaginal challenge model [4-7]. In addition, vaginally applied bNAbs protected macaques from simian-human immunodeficiency virus vaginal challenge [8,9]. An HIV vaccine may therefore be required to elicit potent, long-lasting HIV-specific antibodies in blood and at the genital mucosa, where the virus is first encountered. In the RV144 human vaccine trial that showed moderate efficacy, HIV-specific V1V2 binding antibodies, particularly of the IgG3 subclass, were found to correlate with a reduced risk of HIV infection $[10-12]$. However, as no mucosal sampling was done in this vaccine trial, the presence of these potentially protective antibodies in the genital tract could not be assessed.

HIV-specific binding and neutralizing antibodies have been described in the genital tract of HIV-infected women [13-15], and in highly exposed, but persistently HIV seronegative women [16-18]. HIV-specific antibodies from lower genital tract secretions have been shown to be predominantly $\operatorname{IgG}$ rather than $\operatorname{IgA}$, suggesting that transudation of systemic HIV-specific IgG antibodies contributes to IgG dominance at this mucosal surface [13,19-21]. The neonatal receptor $(\mathrm{FCRn})$ is involved in $\operatorname{IgG}$ transport across polarised epithelial cells lining mucosal surfaces such as the singlelayered columnar epithelial cells of the endocervical canal, in a $\mathrm{pH}$-dependent manner [22]. B cells have also been identified in tissue from the genital tract of HIV-infected women [23-25], suggesting that there is potentially also local production of antibodies from resident $\mathrm{B}$ cells in addition to transudation of antibodies from blood.

Natural HIV infection studies have shown that a proportion of HIV-infected individuals develop bNAbs in their plasma, generally after many years of infection [26-30]. The targets of these bNAbs on the HIV envelope have been mapped to the CD4bs, the glycan at 332, the V1V2 domain, the membrane proximal external (MPER) region, and the gp120-gp41 interface [31,32]. Approximately $20 \%$ of HIV-infected individuals in the CAPRISA 002 cohort developed plasma bNAbs after 2-4 years of infection [27]. In this study, we investigated whether HIV-specific bNAbs are present in genital secretions from these HIV-infected women who developed breadth systemically, and whether these antibodies recognized common binding and neutralization epitopes.

\section{Methods}

\section{Study participants}

Plasma and genital secretions collected by cervicovaginal lavages (CVLs) and/or Softcups were obtained from
13 women in the CAPRISA 002 and CAPRISA 004 cohorts, from Kwa-Zulu Natal, South Africa [33-35] (Supplementary Table 1, http://links.lww.com/QAD/ A883). This study was approved by the Human Research Ethics Committees of the University of Witwatersrand, University of KwaZulu-Natal and University of Cape Town. All participants provided written informed consent.

\section{Collection of genital secretions}

CVL samples were collected as previously described [36]. Each woman underwent a speculum examination during which her cervix was irrigated with a lavage of $10 \mathrm{ml}$ sterile saline. Aspirated saline was transferred to a clean $15 \mathrm{ml}$ tube and centrifuged at $2300 \mathrm{rpm}$ for $10 \mathrm{~min}$ to remove cells. Supernatants were harvested and stored at $-80^{\circ} \mathrm{C}$. In addition, cervical secretions were collected using a Softcup Menstrual cup (EuroFemPro, the Netherlands) and processed as previously described with modifications [37]. For this, the Softcup was inserted into the vagina for a minimum of $1 \mathrm{~h}$ by a clinician, placed into a $50 \mathrm{ml}$ tube and centrifuged [38]. The fluid phase was collected into an eppendorf tube and the volume measured. The pellet was resuspended and centrifuged in $300 \mu \mathrm{l}$ PBS to increase antibody recovery and the fluid phases combined to a total volume of $500 \mu l$. This was used for $\operatorname{IgG}$ purification on the same day.

\section{Immunoglobulin isolation and quantification}

IgG antibodies were isolated using Protein G (Pierce/ Thermo Scientific), whereas IgA was isolated by Peptide M (InvivoGen) as previously described [39]. The final fractions were concentrated using $50000 \mathrm{MW}$ concentrators (Millipore). Total IgG and IgA concentrations in plasma, CVLs and Softcup secretions were quantitated by ELISA, as previously described [40]. High proteinbinding 96-well microplates (Nalge Nunc International, Rochester, New York, USA) were coated with $4 \mu \mathrm{g} / \mathrm{ml}$ goat polyclonal antihuman IgA or IgG (Jackson ImmunoResearch Laboratories, West Grove, Pennsylvania, USA), and then blocked with $5 \%$ goat serum in PBS$0.05 \%$ Tween 20 . Duplicates of two-fold serially diluted samples and a human Immunoglobulin (Ig) reference serum (Human Immunoglobulin Calibrator; Binding Site, Birmingham, UK) were added to the plates and incubated for $1 \mathrm{~h}$ at $37^{\circ} \mathrm{C}$. The captured Ig was detected after consecutive incubations with biotin-labelled goat $\mathrm{F}\left(\mathrm{ab}^{\prime}\right) 2$ specific for human IgA or IgG (BioSource, Camarillo, California, USA) and horseradish (HRP)labelled avidin (Sigma, St. Louis, Missouri, USA). The ELISA was developed with TMB substrate (Thermo Fisher Scientific, Rockford, Illinois, USA) and stopped with a $1 \mathrm{M} \mathrm{H}_{2} \mathrm{SO}_{4}$ solution. The plates were read at $450 \mathrm{~nm}$ on a microplate reader (Molecular Devices, Sunnyvale, California, USA). A standard curve was run on each plate with serial dilutions of a commercial human IgG (Sigma-Aldrich) or IgA (Jackson Immunoresearch, Pennsylvania, USA) to calculate antibody concentrations. 


\section{Binding antibody multiplex assay}

Binding antibodies to HIV proteins and peptides were measured using a customized HIV binding antibody multiplex assay (BAMA), as previously described [10,41]. The HIV antigens used included: consensus gp120 Env (Con6 gp120), clade C gp140 Env trimer (1086 Trimer), clade C TV1 gp140, Group M consensus gp140 Env (ConS gp140), clade B gp70 V1V2 fusion protein (gp70_V1V2), a clade C V1V2 fusion protein (1086_V1V2), clade B MPER tetramer (MPR.03) and gp41 (Immunodiagnostics, Woburn, Massachusetts, USA). Carboxylated fluorescent beads (Luminex Corp., Austin, Texas, USA) were covalently coupled to purified HIV antigens and incubated with clinical samples at various dilutions. CVL supernatants (not purified for $\mathrm{IgG}$ ) were used at a $1: 5$ dilution, whereas plasma antibodies were measured from a titrated dilution $(1: 100$ to $1: 312500)$. HIV-specific total $\operatorname{IgG}$ and $\operatorname{IgG} 3$ were detected using PE-conjugated mouse antihuman IgG and IgG3 (both Southern Biotech, Birmingham, Alabama, USA), respectively. The beads were washed and acquired on a Bio-Plex instrument (Bio-Rad) and results expressed as mean fluorescence intensity (MFI). Responders had MFI 100 or more. The specific activity (MFI*dilution/ antibody concentration) was calculated for genital tract IgG binding to account for variability in antibody levels recovered from different women. Responders had specific activity more than 0.01 .

\section{HIV neutralization assays}

Neutralization was measured using HIV-Env pseudotyped viruses in the TZM-bl assay. Envelope genes were either cloned previously in our laboratory [42] or obtained from the NIH AIDS Research and Reference Reagent Program. This included one Tier 1 virus (SF162.LS) and three Tier 2 viruses (ConC, CAP45.G3 and TRO.11). Murine leukaemia virus was included in the assay as a negative control. Neutralization was measured as a reduction in luciferase gene expression after a single round of infection in JC53bl-13 cells, also known as TZM-bl cells, with Env-pseudotyped viruses [43]. $\mathrm{IC}_{50}$ was calculated as the $\mathrm{IgG}$ concentration causing a $50 \%$ reduction of relative light units.

\section{Epitope mapping}

For epitope mapping via ELISA, plates were coated with ConC gp120 proteins or with an MPER peptide (MPR.03). The ELISA was performed using purified IgG, as described above. Antibody binding to wild-type gp120 but not mutant gp120 (containing an N332A mutation), indicated dependence on the glycan at position 332. Direct antibody binding to the MPR.03 peptide was used to demonstrate the presence of MPERspecific IgG. For mapping via neutralization, viruses containing mutations at key epitopes were used in the neutralization assay, described earlier. This included ConC N160A, CAP45.G3 K169E and TRO.11 N332A mutants, used to map bNAb epitopes targeting sites in the V2 and V3 regions, shown using monoclonal antibodies targeting these sites (data not shown). A reduction in $\mathrm{IC}_{50}$ of the mutant virus compared with the wild-type virus was used to identify the epitope specificities of the isolated IgGs.

\section{Statistical analysis}

The Mann-Whitney test was used for independent sample comparisons and a Wilcoxon matched-pairs signed rank test was performed for dependent sample comparisons, using GraphPad Prism version 5.0 (GraphPad Software, La Jolla, California, USA). All tests were two-tailed and $P$ values of less than 0.05 were considered significant.

\section{Results}

\section{Higher concentrations of $\operatorname{IgG}$ than $\lg A$ isotypes in genital secretions}

The quantity of total IgG and IgA antibodies isolated from matched plasma and genital samples of women, previously identified as having plasma bNAbs, was investigated. CVL samples were initially obtained from seven antiretroviral therapy (ART)-naive women in the CAPRISA 002 cohort at 3 years postinfection [24]. The concentration of total IgA was negligible in genital secretions with a mean value of less than $1 \mu \mathrm{g} / \mathrm{ml}$, whereas in plasma the mean value was $359 \mu \mathrm{g} / \mathrm{ml}$. Overall, IgG concentrations were 2 logs greater and significantly higher than IgA concentrations in both plasma $(P=0.016)$ and $\operatorname{CVL}(P=0.016)$ (Fig. 1a).

To determine whether these antibodies were HIVspecific, we tested them in a gp120 ELISA (Fig. 1b). CVL IgG antibodies bound gp120 at a median titer of $1: 34$, whereas the plasma HIV-specific IgG binding titer was $3 \operatorname{logs}$ higher at $1: 53697$. HIV-specific IgA antibodies in plasma were detected at a median titer of $1: 266$. None of the individuals had HIV-specific IgA detected in CVL, with binding titers at the same level as background. Given this, we focused the rest of the study on $\operatorname{IgG}$ antibodies. In order to accurately compare HIV-specific IgG concentrations in plasma and CVL, we calculated the ratio of HIV-specific to total IgG. Even though plasma consistently had higher titers of IgG than CVL, the median HIVspecific activity was similar in CVL and plasma (Fig. 1c).

In order to optimize sample collection for neutralizing antibody assays, we explored the use of the Softcup for collecting genital secretions. As this method requires fresh sample processing, we recruited four of the women with bNAbs from the CAPRISA 002 cohort who were by that time on ART, but still had detectable neutralization titers (Mkhize, unpublished data) along with an additional six chronically HIV-infected women from the CAPRISA 004 cohort who also developed plasma bNAbs 
(a)

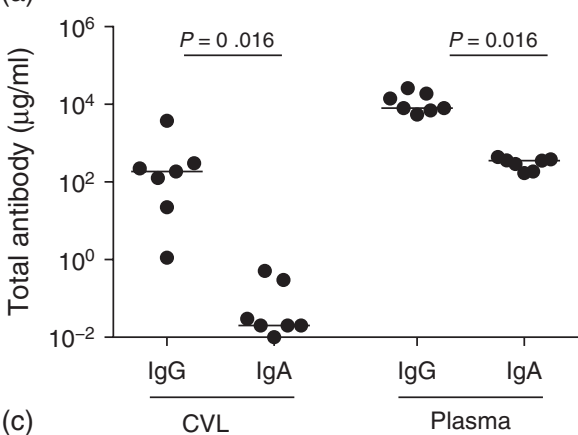

(c)

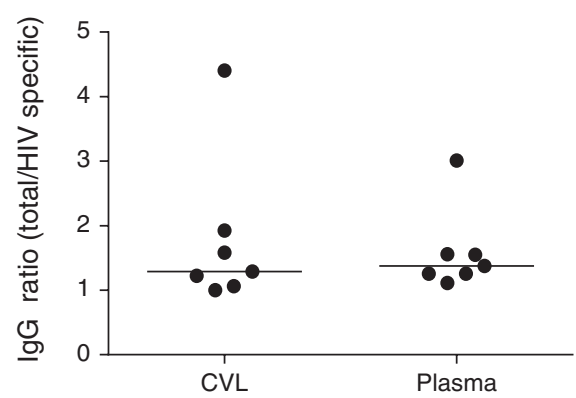

(b)

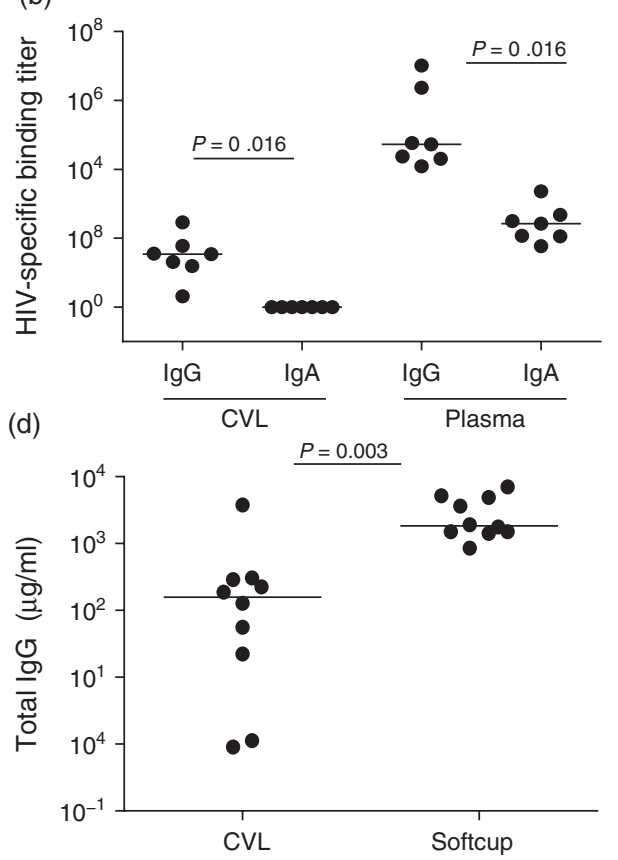

Fig. 1. Detection of total and HIV-specific immunoglobulins in the female genital tract. (a) Quantification of immunoglobulin (Ig)G and IgA concentrations in cervicovaginal lavage (CVL) and plasma of 7 CAPRISA 002 women with broadly neutralizing activity. (b) gp120-specific binding of IgG and IgA antibodies purified from CVL and plasma. (c) Ratio of total IgG to HIV-specific IgG concentrations in CVL and plasma from the 7 CAPRISA 002 women, based on 17b mAb standard curve for gp120 IgG. (d) Comparison of total IgG yields from CVL (from CAPRISA 002) and genital secretions collected using Softcup from 10 women in the CAPRISA 002 and 004 cohorts.

(Madzivhandila, unpublished data). We compared the yields of total $\mathrm{IgG}$ obtained from CVL to those recovered from the genital tract via the Softcup in all 10 women. The total IgG recovered from CVL varied amongst the participants with a range of $0.9-3773 \mu \mathrm{g} / \mathrm{ml}$, whereas the total IgG collected via Softcup was more consistent with a range of $1060-6752 \mu \mathrm{g} / \mathrm{ml}$ (Fig. 1d). Compared with CVL, the Softcup method resulted in a 13-fold higher level of total IgG $(P=0.003)$.

\section{HIV-specific antibodies in cervicovaginal lavage recognize multiple HIV envelope antigens}

The kinetics, magnitude, and specificities of antibodies in CVL and plasma collected from women at 1, 2 and 3 years postinfection were compared using BAMA. HIV-specific IgG binding reactivity to all eight HIV Env antigens was detected in CVLs and plasma, and as there was little difference between time points, the data were analysed together (Fig. 2). Antibodies to gp120, gp140, gp41 and MPER were present at all time points at similar levels in CVL and plasma. Only antibodies to the V1V2 antigens differed, with genital tract IgG binding levels significantly lower than plasma [1086_V1V2 $(P=0.0001)$; gp70_V1V2 $(P=0.0002)]$. IgG responses to gp70_V1V2 were better than to $1086 \_$V1V2 and these were detected in four of seven women at 1 or more time points. Overall, these data suggest that HIV-specific IgG antibody specificities in the genital compartment generally match those found in blood plasma, even though levels were lower in the genital compartment.

Considering the important role of the IgG3 subclass in HIV-1 vaccine studies [10,11] and bNAbs [44,45], we further examined this subclass binding response in the genital compartment. Two individuals, CAP256 and CAP177, were found to have detectable HIV-specific IgG3 responses in both plasma and genital compartments (Fig. 3). For CAP256, plasma IgG3 antibodies to all antigens remained at high titers over time although responses to gp70_V1V2 decayed slightly by 3 years postinfection. Declining responses to all antigens were also observed in CVL although V1V2 IgG3 responses were not detected at any time-point. Plasma from CAP177 contained HIV-specific IgG3 to all antigens except gp70_V1V2. In this individual, low titers of these antibodies were also found in the CVL at 1 year postinfection but declined to below the levels of detection at later time points. This is likely because of the low overall concentrations of $\mathrm{IgG}$ antibodies recovered from this participant at the 2- and 3-year time points (not shown).

\section{HIV-specific neutralizing antibody activity in the female genital tract}

Next, we determined whether HIV-specific antibodies in CVLs had neutralizing activity. All seven HIV-infected 

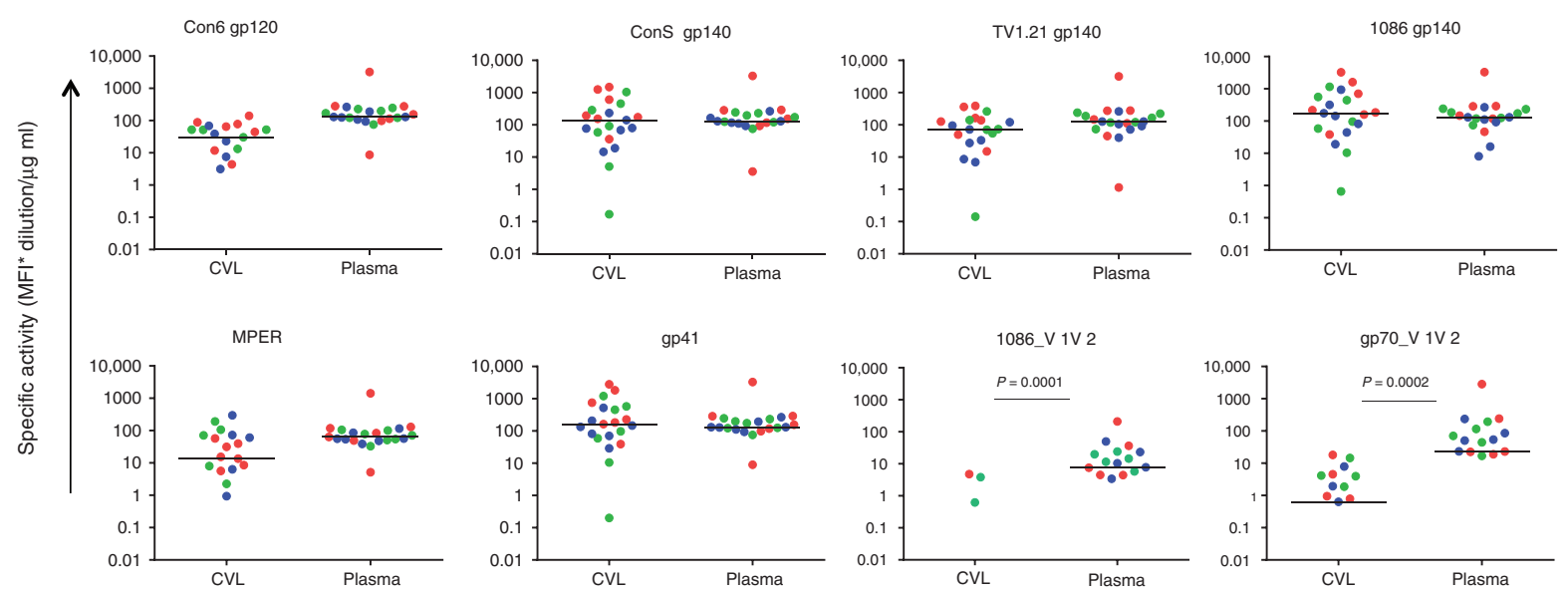

Fig. 2. HIV-specific activity of immunoglobulin (Ig)G antibodies in cervicovaginal lavage (CVL) and plasma. IgG-binding antibodies were measured in CVL and plasma from the 7 CAPRISA 002 women who developed broadly neutralizing antibodies. Dots represent CVL and plasma samples from 1 year (red), 2 years (green) and 3 years (blue) post-HIV infection. Reactivity to eight antigens was evaluated via the HIV-1 BAMA. The median fluorescence intensity (MFI) values were normalized to total IgG concentration (specific activity). Samples that had MF1 less than 100 were considered nonresponders and had no values for specific activity, therefore the points are not reflected on the plots. Responders had a specific activity more than 0.01 for all antigens.

women previously shown to have bNAbs [27] had HIVspecific IgG antibodies that neutralized SF162, an easy-to-neutralize Tier 1 virus (Fig. 4a). Furthermore, they also all showed dose-dependent activity against ConC, a Tier 2 virus, although this did not reach 50\% neutralization in three of seven women. The potent neutralization of the more sensitive SF162 suggested that
Tier 1 neutralizing antibodies were more prevalent in $\mathrm{CVL}$, as is also seen in plasma. However, there was a wide range in $\mathrm{IC}_{50}$ values among these samples with CAP8 showing the highest level of activity against both viruses.

As antibody concentrations were generally low in CVLs, we next tested $\operatorname{IgG}$ antibodies freshly collected from these
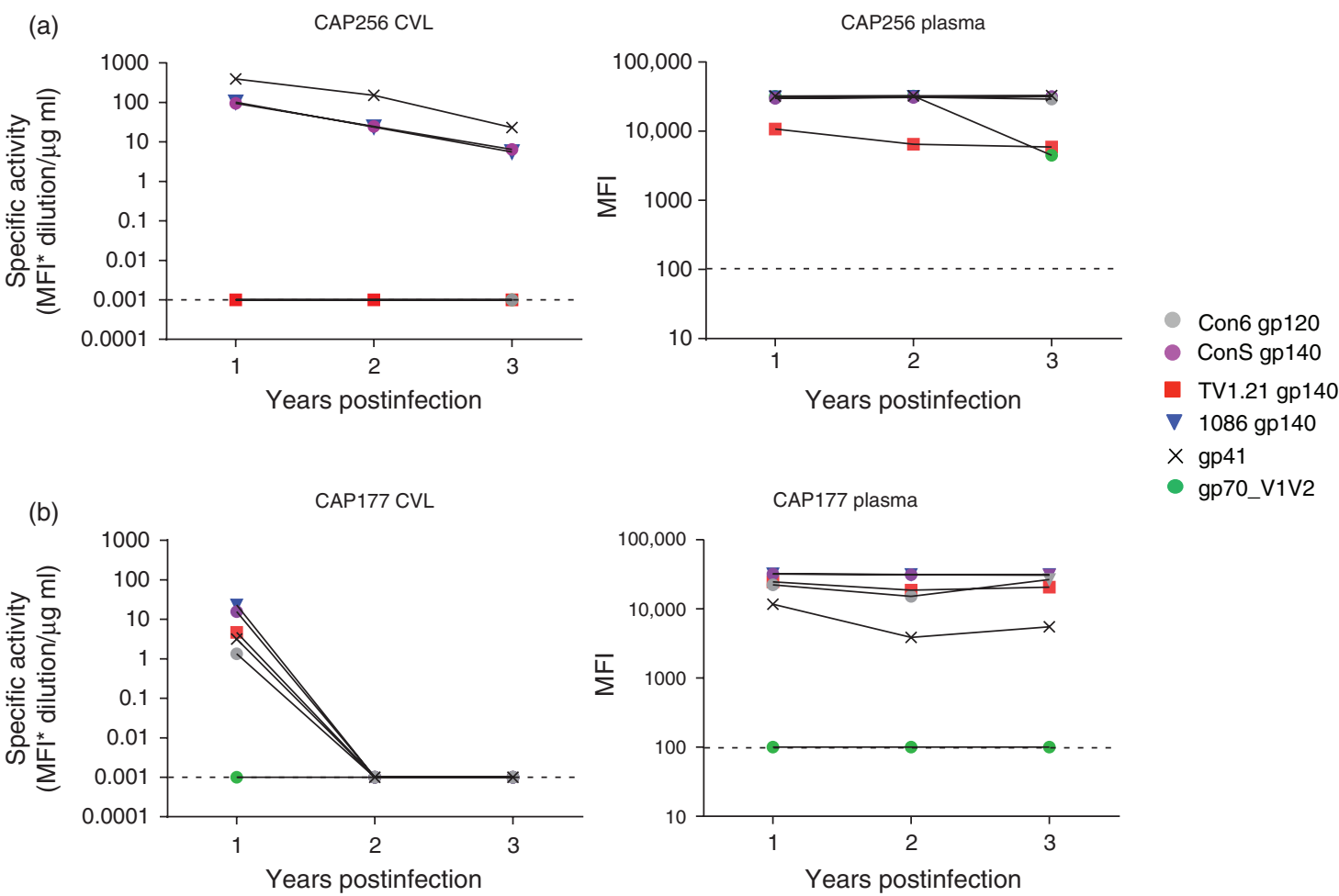

Fig. 3. Immunoglobulin (Ig)G3 binding to HIV-specific antigens. IgG3 responses were measured against Env antigens at 1, 2 and 3 years post-HIV infection. Responses were detected in CAP256 (a) and CAP177 (b), represented as specific activity for cervicovaginal lavage (left panel) and MFI for plasma samples (right panel). 
(a)

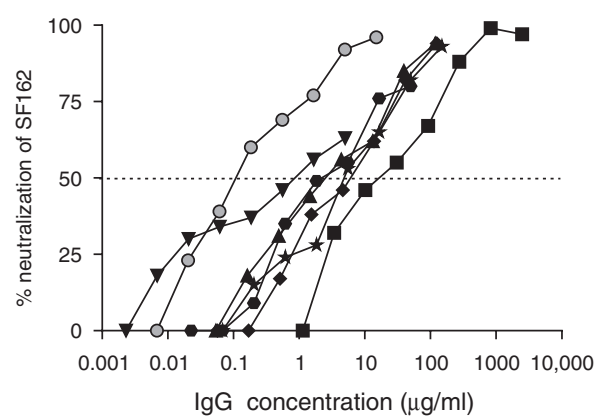

(b)

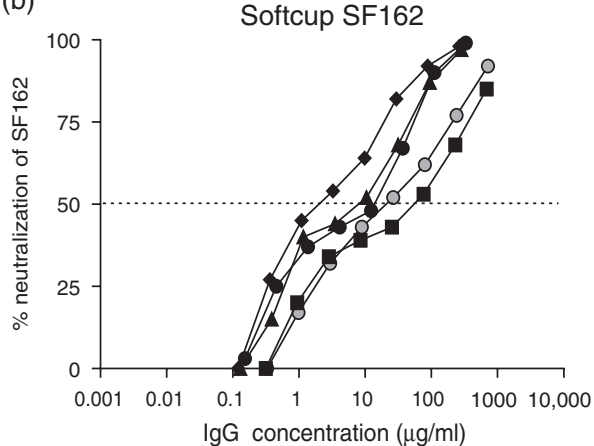

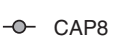

$\rightarrow$ CAP177

- CAP206

$\rightarrow$ CAP248

- CAP255

- CAP256

* CAP257

- CAP8

- CAP248

- CAP292

- CAP309

- CAP341

CAP341

Fig. 4. Neutralization of HIV by purified immunoglobulin (Ig)G from the genital tract. SF162 (Tier 1) and ConC (Tier 2) viruses were tested in a TZM-bI neutralization assay using IgG isolated from cervicovaginal lavage supernatant (a) and Softcup (b) from women in the CAPRISA 002 and 004 cohorts. The dotted line represents the $\mathrm{IC}_{50}$.

women using cervical Softcups to improve IgG recovery [38] and allow for more neutralization assays to be performed (Supplementary Table 1, http://links.lww. com/QAD/A883). This included two CAPRISA 002 women (CAP8 and CAP248) who were receiving ART at the time of Softcup sampling, as well as three additional women from the CAPRISA 004 cohort who were ARTnaive. Softcup-derived IgGs isolated from five of these women were able to neutralize both SF162 and ConC (Fig. 4b). In particular, the ability of all samples to neutralize ConC with measurable $\mathrm{IC}_{50}$ titers was a notable improvement over the CVL preparations. This is despite the fact that some of these women were on ART that is known to reduce antibody titers [46-48]. Overall, the $\mathrm{IC}_{50}$ values of the curves suggested that $\mathrm{IgG}$ recovered from the Softcup provided a more consistent preparation compared with CVL.

\section{Mapping of genital tract IgG antibody specificities}

We previously showed that the plasma bNAbs in CAP177 were dependent on the glycan at position 332 in the V3 region of gp120 [27]. To determine whether genital tract antibodies shared the same specificity, we used a wild-type gp120 and an N332A mutant protein that lacked this glycan, in an ELISA assay. PGT128, a mAb that is highly dependent on N332 [49] showed significantly less binding to this mutant protein (data not shown). Comparison of $\operatorname{IgG}$ binding levels revealed a four-fold reduction in binding to the mutant protein by $\operatorname{IgG}$ from CVL and a three-fold reduction for plasma IgG (Fig. 5a). This indicated that a subset of antibodies isolated from the CVL of CAP177 targeted the N332 glycan epitope on gp120 similar to the plasma antibodies.

Plasma bNAbs in CAP206 were previously shown to target the MPER of gp41 and bind the MPR.03 peptide in an ELISA assay $[45,50]$. We found that IgG antibodies isolated from both plasma and CVL of CAP206 bound the MPR.03 peptide with comparable levels (Fig. 5a) indicating that antibodies with a similar specificity were present in both compartments.

We next mapped antibodies by neutralization assay using epitope-ablating mutants. For this we used the more abundant IgG collected via Softcup which allowed us to test multiple mutants (Fig. 5b). For CAP8, purified IgG antibodies from cervical Softcups and plasma were sensitive to the N160A mutation in ConC that is characteristic of many V2-dependent antibodies [51,52]. A V2 antibody was previously isolated from blood of donor CAP256 that is sensitive to the K169E mutation [53]. Here we show IgG antibodies from the genital tract of CAP256 were also sensitive to K169E in the CAP45.G3 virus. The presence of N332-dependent antibodies in both genital secretions and plasma from CAP255 was demonstrated using the TRO.11 virus. Although the level of neutralization against the wild-type 
(a)
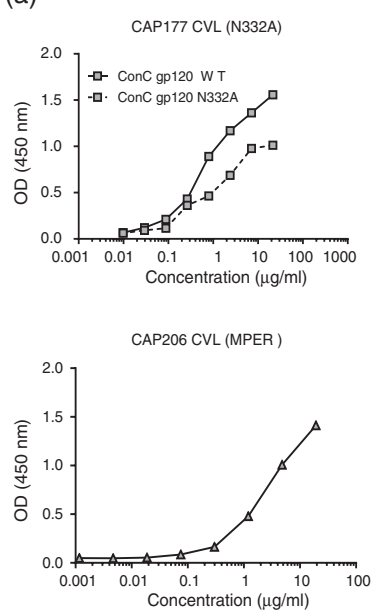

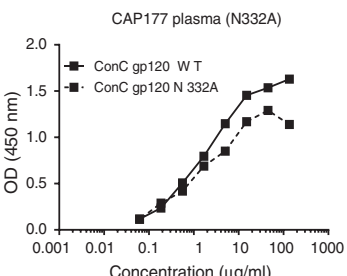

Concentration $(\mu \mathrm{g} / \mathrm{ml})$

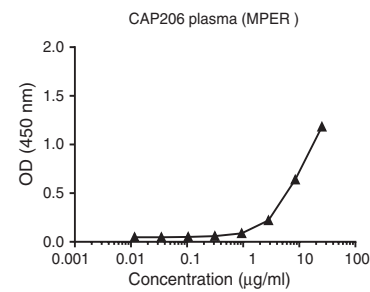

(b)
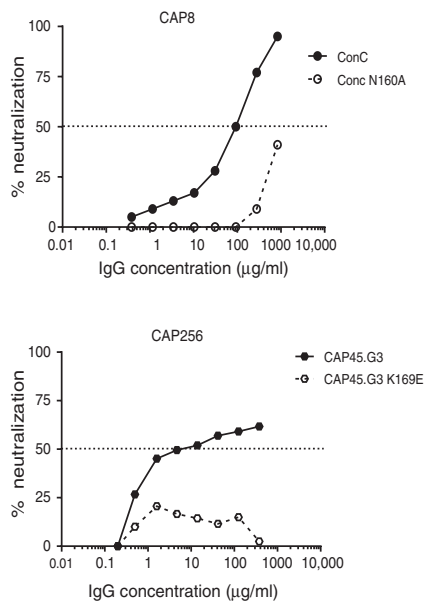

CAP255

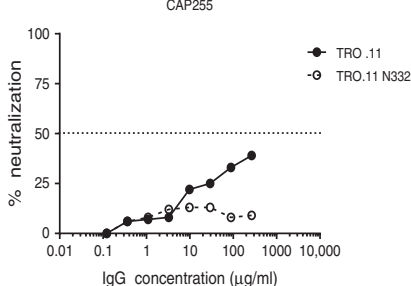

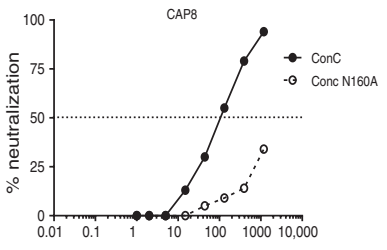

$\lg \mathrm{G}$ concentration $(\mu \mathrm{g} / \mathrm{ml})$

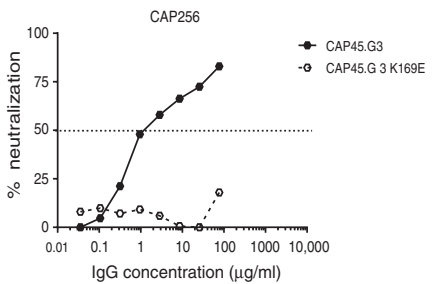

$\mathrm{lgG}$ concentration $(\mu \mathrm{g} / \mathrm{ml})$

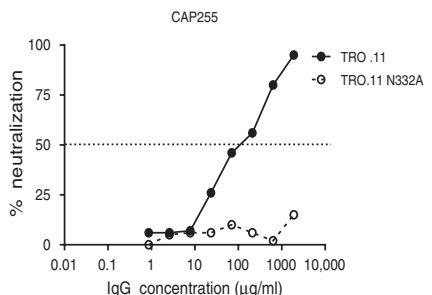

Fig. 5. Epitope mapping of antibody specificities by ELISA (a) and neutralization (b). Cervicovaginal lavage and plasma immunoglobulin (Ig)G antibody specificities in CAP177 at 3 years postinfection were tested by binding to wild-type and N332A mutant gp120, whereas anti-MPER IgG activity in CAP206 was detected at 3 years postinfection in both genital tract and plasma by peptide ELISA (a). Plasma and genital tract IgG antibody from CAP8, CAP256 and CAP255 were mapped by measuring neutralization of wild-type virus and mutant viruses. The dotted lines represent $\mathrm{IC}_{50}$ values (b).

virus was less than 50\% inhibition (probably because of low levels of recoverable HIV-specific antibody), there was almost complete knockout with the N332A mutant. Overall, these data reliably confirmed the presence of identical HIV-specific antibody specificities in both genital secretions and plasma.

\section{Discussion}

We have detected HIV-specific binding and neutralizing IgG antibodies in the female genital tract of HIV-infected women previously shown to have bNAbs in plasma. Overall, these IgG antibodies matched those in plasma, targeting major neutralizing antibody epitopes including V2 and V3 glycans and the MPER of gp41. Binding antibodies to the V1V2 region, previously shown to correlate with protection in the RV144 HIV vaccine trial [12], were also present in the genital tract. The similarity of the antibody specificities detected in genital secretions and plasma suggest that the HIV-specific antibodies (or B cells) are able to transude across the genital mucosa. This further suggests that antibodies elicited by systemic vaccination (or transferred through passive immunization) are likely to reach mucosal surfaces and could contribute to preventing the sexual transmission of HIV.
This study has confirmed earlier reports that HIV-specific responses in genital secretions are almost exclusively of the IgG isotype [13,14,21,54]. The paucity of HIV-specific IgA despite abundant levels of total IgA in lavages of HIVinfected women has also been noted by others [19,5557]. A similar lack of HIV-specific IgA is seen in other mucosal external secretions including breast milk although in digestive mucosal secretions, such as saliva and intestinal surfaces, HIV-specific IgA antibodies predominate [58-60]. Even though $\operatorname{IgG}$ is the dominant isotype in the genital tract, the levels of total $\mathrm{IgG}$ have been reported to vary during the phases of the menstrual cycle $[61,62]$. In this study, sampling of genital secretions was not normalised according to cycle as our focus was on examining the functional properties of genital antibodies which are unlikely to be affected by the menstrual cycle. Interestingly, HIV-specific IgG could be recovered from patients on long-term ART indicating that removal of antigenic stimulation did not ablate the $\operatorname{IgG}$ response in the genital compartment.

Mucosal sampling is particularly challenging for measuring antibody neutralization because of the low levels of IgG in genital secretions as well as interfering components [63]. We therefore isolated and quantified IgG prior to performing neutralization assays. This resulted in variable $\mathrm{HIV}$-specific IgG content (the ratio 
of HIV specific IgG to total $\operatorname{IgG}$ ) probably because large and variable volumes are recovered by CVL. Antibody recovery was significantly improved through the use of the cervical Softcup [64,65], which provided more consistent data and higher IgG recovery from genital fluids. The Softcup collects undiluted samples that are processed immediately [38], and thus are not exposed to freeze-thaw cycles, which may reduce the concentration of $\operatorname{IgG}$ antibodies in CVL [66]. Furthermore, other studies have shown that the endocervix, which is more specifically sampled by Softcup, has more concentrated antibodies than the vagina [60], which is a washout mainly of the vaginal vault. Another possible explanation for the improved recovery of genital IgG is that the Softcup method retains mucus during processing, which has been shown to harbour antibodies and other antiviral proteins [67], whereas during CVL processing mucus is spun down and discarded. The Softcup thus provides a significant improvement on CVL sample collection for the analysis of the humoral immunity to HIV.

The HIV-specific IgG binding activity to most Env antigens tested was similar for plasma and CVL, except for V1V2 antigens where lower concentrations of $\operatorname{IgG}$ at the genital tract made it difficult to detect epitope-specific responses. Although HIV Env-specific IgG reactivity, which encompasses IgG1-4 isotypes, was observed in all individuals, only two had detectable IgG3 responses. These normally short-lived antibodies $[68,69]$ were detected up to 3 years postinfection in plasma and CVL. V1V2-specific IgG3 antibodies were shown to correlate with decreased risk of HIV infection in the RV144 trial [10-12]. Although we were unable to detect V1V2 IgG3 at the genital tract, we suspect this is simply because of lower concentrations in CVL rather than selective exclusion of these antibodies.

The finding of identical specificities among genital and plasma neutralizing IgG antibodies strongly supports a link between the female genital mucosa and blood. This suggests transudation of antibody from blood across the genital mucosa; or trafficking of $\mathrm{B}$ cells from the systemic compartment to become resident mucosal antibody secreting cells [60]. A recent study showed recruitment of IgG-secreting plasma cells to the genital tract of vaccinated rhesus macaques as well as a distinct set of resident cervical reserve epithelial cells that delivered $\operatorname{IgG}$ to the lumen via the neonatal $\mathrm{Fc}$ receptor [70]. The high expression of $\mathrm{FCRn}$ reserve cells in the epithelial layer offers a mechanism by which IgG from the circulation is transferred to the lumen and genital tract external surfaces. Several vaccine studies in humans and primate models have shown HIV or SIV-specific $\mathrm{IgG}$ antibodies in the genital tract $[71,72]$, providing further evidence of transudation of antibodies either from the circulation or migration of plasma cells to the mucosa.
Even though it was not possible to test large panels of viruses because of limited volumes, this study suggests that HIV-specific bNAbs are present in the female genital tract, and overlap in specificity with those present systemically. This study of women naturally infected with HIV provides pertinent insight into which plasmaderived protective antibodies can transude to the genital tract. Our data suggest that systemic vaccine induced or passively infused antibodies would migrate to the genital compartment where they could protect against invading HIV particles.

\section{Acknowledgements}

We thank the participants in the CAPRISA cohorts for providing specimens and the clinical and laboratory teams at CAPRISA for processing samples. Dr Elin Gray provided guidance at the start up of this project and Mary Phoswa provided technical assistance. All gp140, gp120, V1V2 glycoproteins and MPER tetramers were provided by Drs B. Haynes, H. Liao and M.A. Moody (Duke Human Vaccine Institute, USA). We thank the Technology Innovation Agency (TIA) of the Department of Science and Technology (DST) of South Africa, U.S. National Institutes of Health for its Comprehensive International Program of Research on AIDS (CIPRA grant AI51794), NIH/NIAID (UM1AI068618), the Duke Center for AIDS Research (AI064518) and the Columbia University-Southern African Fogarty AIDS International Training and Research Programme (AITRP grant D43TW00231) for the research infrastructure and training that made the CAPRISA 002 acute infection study possible. N.N.M. was funded by the Clinical Infectious Diseases Research Initiative (CIDRI), PRF and the Fogarty AITRP to visit Dr Georgia Tomaras laboratory to perform BAMA assays. P.L.M. is a Wellcome Trust Intermediate Fellow in Public Health and Tropical Medicine (grant 089933/ Z/09/Z).

Role of authors: N.M. designed and conducted experiments, analysed data and wrote the manuscript; R.D. performed neutralization assays; V.A. and N.Y. assisted with the BAMA; D.A. and N.G. arranged collection of Softcup samples; N.G., Q.A.K. and S.S.A.K. provided clinical samples; P.L.M. provided guidance on epitope mapping; J.P. provided guidance on mucosal sampling; G.D.T. supervised the BAMA assay and analysis; and L.M. designed experiments, analysed data and supervised the project. All authors commented on the manuscript.

\section{Conflicts of interest}

There are no conflicts of interest. 


\section{References}

1. UNAIDS. UNAIDS Gap report 2013. Geneva, Switzerland: UNAIDS.

2. Abdool Karim SS, Abdool Karim Q, Baxter C. Antibodies for HIV prevention in young women. Curr Opin HIV AIDS 2015; 10:183-189.

3. Ko SY, Pegu A, Rudicell RS, Yang ZY, Joyce MG, Chen X, et al. Enhanced neonatal $F c$ receptor function improves protection against primate SHIV infection. Nature 2014; 514:642-645.

4. Moldt B, Rakasz EG, Schultz N, Chan-Hui PY, Swiderek K, Weisgrau KL, et al. Highly potent HIV-specific antibody neutralization in vitro translates into effective protection against mucosal SHIV challenge in vivo. Proc Natl Acad Sci U S A 2012; 109:18921-18925.

5. Hessell AJ, Rakasz EG, Tehrani DM, Huber M, Weisgrau KL, Landucci $G$, et al. Broadly neutralizing monoclonal antibodies 2F5 and 4E10 directed against the human immunodeficiency virus type $1 \mathrm{gp} 41$ membrane-proximal external region protect against mucosal challenge by simian-human immunodeficiency virus SHIVBa-L. J Virol 2010; 84:1302-1313.

6. Mascola JR, Stiegler G, VanCott TC, Katinger H, Carpenter CB, Hanson $\mathrm{CE}$, et al. Protection of macaques against vaginal transmission of a pathogenic HIV-1/SIV chimeric virus by passive infusion of neutralizing antibodies. Nat Med 2000; 6:207-210.

7. Baba TW, Liska V, Hofmann-Lehmann R, Vlasak J, Xu W, Ayehunie $S$, et al. Human neutralizing monoclonal antibodies of the IgG1 subtype protect against mucosal simian-human immunodeficiency virus infection. Nat Med 2000; 6:200-206.

8. Moog C, Dereuddre-Bosquet N, Teillaud JL, Biedma ME, Holl V, Van Ham G, et al. Protective effect of vaginal application of neutralizing and nonneutralizing inhibitory antibodies against vaginal SHIV challenge in macaques. Mucosal Immunol 2014; 7:46-56.

9. Veazey RS, Shattock RJ, Pope M, Kirijan JC, Jones J, Hu Q, et al. Prevention of virus transmission to macaque monkeys by a vaginally applied monoclonal antibody to HIV-1 gp120. Nat Med 2003; 9:343-346.

10. Yates NL, Liao HX, Fong $\mathrm{Y}$, deCamp A, Vandergrift NA, Williams WT, et al. Vaccine-induced Env V1-V2 IgG3 correlates with lower HIV-1 infection risk and declines soon after vaccination. Sci Transl Med 2014; 6:228-239.

11. Chung AW, Ghebremichael M, Robinson H, Brown E, Choi I, Lane $S$, et al. Polyfunctional Fc-effector profiles mediated by IgG subclass selection distinguish RV144 and VAX003 vaccines. Sci Transl Med 2014; 6:228-238.

12. Haynes BF, Gilbert PB, McElrath MJ, Zolla-Pazner S, Tomaras $\mathrm{GD}$, Alam SM, et al. Immune-correlates analysis of an HIV1 vaccine efficacy trial. N Engl J Med 2012; 366:12751286.

13. Wei Q, Moldoveanu Z, Huang WQ, Alexander RC, Goepfert PA, Mestecky J. Comparative evaluation of HIV-1 neutralization in external secretions and sera of HIV-1-infected women. Open AIDS J 2012; 6:293-302.

14. Wright PF, Kozlowski PA, Rybczyk GK, Goepfert P, Staats HF, VanCott TC, et al. Detection of mucosal antibodies in HIV type 1-infected individuals. AIDS Res Hum Retroviruses 2002; 18:1291-1300.

15. Mestecky J, Wei Q, Alexander R, Raska M, Novak J, Moldoveanu Z. Humoral immune responses to HIV in the mucosal secretions and sera of HIV-infected women. Am / Reprod Immunol 2014; 71:600-607.

16. Broliden K, Hinkula J, Devito C, Kiama P, Kimani J, Trabbatoni $\mathrm{D}$, et al. Functional HIV-1 specific IgA antibodies in HIV-1 exposed, persistently IgG seronegative female sex workers. Immunol Lett 2001; 79:29-36.

17. Devito C, Hinkula J, Kaul R, Kimani J, Kiama P, Lopalco L, et al. Cross-clade HIV-1-specific neutralizing IgA in mucosal and systemic compartments of HIV-1-exposed, persistently seronegative subjects. J Acquir Immune Defic Syndr 2002; 30:413420.

18. Seaton KE, Ballweber L, Lan A, Donathan M, Hughes S, Vojtech $L$, et al. HIV-1 specific IgA detected in vaginal secretions of HIV uninfected women participating in a microbicide trial in Southern Africa are primarily directed toward gp120 and gp140 specificities. PLOS One 2014; 9:e101863.
19. Mestecky J, Jackson S, Moldoveanu Z, Nesbit LR, Kulhavy R, Prince $S$ J, et al. Paucity of antigen-specific IgA responses in sera and external secretions of HIV-type 1-infected individuals. AIDS Res Hum Retroviruses 2004; 20:972-988.

20. Buchacz K, Parekh BS, Padian NS, van der Straten A, Phillips S, Jonte $\mathrm{J}$, et al. HIV-specific IgG in cervicovaginal secretions of exposed HIV-uninfected female sexual partners of HIV-infected men. AIDS Res Hum Retroviruses 2001; 17:1689-1693.

21. Belec L, Dupre T, Prazuck T, Tevi-Benissan C, Kanga JM, Pathey $\mathrm{O}$, et al. Cervicovaginal overproduction of specific IgG to human immunodeficiency virus (HIV) contrasts with normal or impaired IgA local response in HIV infection. J Infect Dis 1995; 172:691-697.

22. Li Z, Palaniyandi S, Zeng R, Tuo W, Roopenian DC, Zhu X. Transfer of IgG in the female genital tract by MHC class Irelated neonatal $\mathrm{Fc}$ receptor ( $\mathrm{FCRn}$ ) confers protective immunity to vaginal infection. Proc Natl Acad Sci U S A 2011; 108:4388-4393.

23. Trifonova RT, Lieberman J, van Baarle D. Distribution of immune cells in the human cervix and implications for HIV transmission. Am J Reprod Immunol 2014; 71:252-264.

24. Lee SK, Kim CJ, Kim DJ, Kang JH. Immune cells in the female reproductive tract. Immune Netw 2015; 15:16-26.

25. Nkwanyana NN, Gumbi PP, Roberts L, Denny L, Hanekom W, Soares $A$, et al. Impact of human immunodeficiency virus 1 infection and inflammation on the composition and yield of cervical mononuclear cells in the female genital tract. Immunology 2009; 128:e746-e757.

26. Hraber P, Seaman MS, Bailer RT, Mascola JR, Montefiori DC, Korber BT. Prevalence of broadly neutralizing antibody responses during chronic HIV-1 infection. AIDS (London, England) 2014; 28:163-169.

27. Gray ES, Madiga MC, Hermanus T, Moore PL, Wibmer CK, Tumba NL, et al. The neutralization breadth of HIV-1 develops incrementally over four years and is associated with CD4+ T cell decline and high viral load during acute infection. J Virol 2011; 85:4828-4840.

28. Sather DN, Stamatatos L. Epitope Specificities of Broadly Neutralizing Plasmas from HIV-1 Infected Subjects. Vaccine 2010; 28S2:B8-B12.

29. Doria-Rose NA, Connors M. Antibody-secreting B cells in HIV infection. Curr Opin HIV AIDS 2009; 4:426-430.

30. Tomaras GD, Binley JM, Gray ES, Crooks ET, Osawa K, Moore $\mathrm{PL}$, et al. Polyclonal $\mathbf{B}$ cell responses to conserved neutralization epitopes in a subset of HIV-1-infected individuals. J Virol 2011; 85:11502-11519.

31. Wibmer CK. Moore PL; Morris L. HIV broadly neutralizing antibody targets. Curr Opin HIV AIDS 2015; 10:135-143.

32. Klein F, Mouquet H, Dosenovic P, Scheid JF, Scharf L, Nussenzweig MC. Antibodies in HIV-1 vaccine development and therapy. Science 2013; 341:1199-1204.

33. van Loggerenberg F, Mlisana K, Williamson C, Auld SC, Morris L, Gray CM, et al. Establishing a cohort at high risk of HIV infection in South Africa: challenges and experiences of the CAPRISA 002 acute infection study. PLOS One 2008; 3:e1954.

34. Mlisana K, Werner L, Garrett NJ, McKinnon LR, van Loggerenberg $\mathrm{F}$, Passmore JA, et al. Rapid disease progression in HIV-1 subtype C-infected South African women. Clin Infect Dis 2014; 59:1322-1331.

35. Garrett NJ, Werner L, Naicker N, Naranbhai V, Sibeko S, Samsunder N, et al. HIV disease progression in seroconvertors from the CAPRISA 004 tenofovir gel preexposure prophylaxis trial. I Acquir Immune Defic Syndr 2015; 68:55-61.

36. Bebell LM, Passmore JA, Williamson C, Mlisana K, Iriogbe I, van Loggerenberg $F$, et al. Relationship between levels of inflammatory cytokines in the genital tract and CD4+ cell counts in women with acute HIV-1 infection. J Infect Dis 2008; 198:710714.

37. Shukair SA, Allen SA, Cianci GC, Stieh DJ, Anderson MR, Baig $\mathrm{SM}$, et al. Human cervicovaginal mucus contains an activity that hinders HIV-1 movement. Mucosal Immunol 2013; 6:427434.

38. Archary D, Liebenberg LJ, Werner L, Tulsi S, Majola N, Naicker $\mathrm{N}$, et al. Randomized cross-sectional study to compare HIV-1 specific antibody and cytokine concentrations in female genital secretions obtained by menstrual cup and cervicovaginal lavage. PLOS ONE 2015; 10:e 0131906. 
39. Tomaras GD, Ferrari G, Shen X, Alam SM, Liao HX, Pollara J, et al. Vaccine-induced plasma IgA specific for the $\mathbf{C} 1$ region of the HIV-1 envelope blocks binding and effector function of IgG. Proc Natl Acad Sci U S A 2013; 110:9019-9024.

40. Gray ES, Moody MA, Wibmer CK, Chen X, Marshall D, Amos I, et al. Isolation of a monoclonal antibody that targets the alpha2 helix of gp120 and represents the initial autologous neutralizing-antibody response in an HIV-1 subtype C-infected individual. J Virol 2011; 85:7719-7729.

41. Tomaras GD, Yates NL, Liu P, Qin L, Fouda GG, Chavez LL, et al. Initial B-cell responses to transmitted human immunodeficiency virus type 1: virion-binding immunoglobulin $M$ (IgM) and IgG antibodies followed by plasma antigp41 antibodies with ineffective control of initial viremia. I Virol 2008; 82:12449-12463.

42. Gray ES, Moore PL, Choge IA, Decker JM, Bibollet-Ruche F, Li $\mathrm{H}$, et al. Neutralizing antibody responses in acute human immunodeficiency virus type 1 subtype $\mathbf{C}$ infection. / Virol 2007; 81:6187-6196.

43. Montefiori DC. Evaluating neutralizing antibodies against HIV, SIV, and SHIV in luciferase reporter gene assays. Curr Protoc Immunol 2005Chapter 12:Unit 12.11:1-15.

44. Scharf O, Golding H, King LR, Eller N, Frazier D, Golding B, et al. Immunoglobulin G3 from polyclonal human immunodeficiency virus (HIV) immune globulin is more potent than other subclasses in neutralizing HIV type 1. J Virol 2001; 75:65586565.

45. Gray ES, Madiga MC, Moore PL, Mlisana K, Abdool Karim SS, Binley JM, et al. Broad neutralization of human immunodeficiency virus type 1 mediated by plasma antibodies against the gp41 membrane proximal external region. I Virol 2009; 83:11265-11274.

46. Morris L, Binley JM, Clas BA, Bonhoeffer S, Astill TP, Kost R, et al. HIV-1 antigen-specific and -nonspecific B cell responses are sensitive to combination antiretroviral therapy. J Exp Med 1998; 188:233-245.

47. Falkensammer B, Freissmuth D, Hubner L, Speth C, Dierich MP, Stoiber $\mathrm{H}$. Changes in HIV-specific antibody responses and neutralization titers in patients under ART. Front Biosci 2007; 12:2148-2158.

48. Gach JS, Achenbach CJ, Chromikova V, Berzins B, Lambert N, Landucci $G$, et al. HIV-1 specific antibody titers and neutralization among chronically infected patients on long-term suppressive antiretroviral therapy (ART): a cross-sectional study. PLoS One 2014; 9:e85371.

49. Walker LM, Huber M, Doores KJ, Falkowska E, Pejchal R, Julien $\mathrm{JP}$, et al. Broad neutralization coverage of HIV by multiple highly potent antibodies. Nature $2011 ; 477: 466-470$.

50. Morris L, Chen X, Alam M, Tomaras G, Zhang R, Marshall DJ, et al. Isolation of a human anti-HIV gp41 membrane proximal region neutralizing antibody by antigen-specific single $B$ cell sorting. PLoS One 2011; 6:e23532.

51. Walker LM, Phogat SK, Chan-Hui PY, Wagner D, Phung P, Goss $J$, et al. Broad and potent neutralizing antibodies from an African donor reveal a new HIV-1 vaccine target. Science 2009; 326:285-289.

52. Bonsignori M, Montefiori DC, Wu X, Chen X, Hwang KK, Tsao $C Y$, et al. Two distinct broadly neutralizing antibody specificities of different clonal lineages in a single HIV-1-infected donor: implications for vaccine design. J Virol 2012; 86:46884692.

53. Doria-Rose NA, Schramm CA, Gorman J, Moore PL, Bhiman JN, DeKosky BJ, et al. Developmental pathway for potent V1V2directed HIV-neutralizing antibodies. Nature 2014; 509:55-62.

54. Moldoveanu Z, Mestecky J. Mucosal antibody responses to HIV. Methods Mol Biol 2009; 485:333-345.
55. Mestecky J, Wright PF, Lopalco L, Staats HF, Kozlowski PA, Moldoveanu $Z$, et al. Scarcity or absence of humoral immune responses in the plasma and cervicovaginal lavage fluids of heavily HIV-1-exposed but persistently seronegative women. AIDS Res Hum Retroviruses 2011; 27:469-486.

56. McKinley SA, Chen A, Shi F, Wang S, Mucha PJ, Forest MG, et al. Modeling neutralization kinetics of HIV by broadly neutralizing monoclonal antibodies in genital secretions coating the cervicovaginal mucosa. PLoS One 2014; 9:e100598.

57. Alexander R, Mestecky J. Neutralizing antibodies in mucosal secretions: IgG or IgA? Curr HIV Res 2007; 5:588-593.

58. Fouda GG, Yates NL, Pollara J, Shen X, Overman GR, Mahlokozera $\mathrm{T}$, et al. HIV-specific functional antibody responses in breast milk mirror those in plasma and are primarily mediated by IgG antibodies. J Virol 2011; 85:9555-9567.

59. Mestecky J. Humoral immune responses to the human immunodeficiency virus type-1 (HIV-1) in the genital tract compared to other mucosal sites. J Reprod Immunol 2007; 73:86-97.

60. Bard E, Riethmuller D, Biichle S, Meillet D, Pretet JL, Mougin C, et al. Validation of a high sensitive immunoenzymatic assay to establish the origin of immunoglobulins in female genital secretions. I Immunoassay Immunochem 2002; 23:145-162.

61. Wira CR, Fahey JV. A new strategy to understand how HIV infects women: identification of a window of vulnerability during the menstrual cycle. AIDS 2008; 22:1909-1917.

62. Kutteh WH, Prince SJ, Hammond KR, Kutteh CC, Mestecky J. Variations in immunoglobulins and IgA subclasses of human uterine cervical secretions around the time of ovulation. Clin Exp Immunol 1996; 104:538-542.

63. Mestecky J, Moldoveanu Z, Russell MW. Immunologic uniqueness of the genital tract: challenge for vaccine development. Am I Reprod Immunol 2005; 53:208-214.

64. Boskey ER, Moench TR, Hees PS, Cone RA. A self-sampling method to obtain large volumes of undiluted cervicovaginal secretions. Sex Transm Dis 2003; 30:107-109.

65. Lai SK, O'Hanlon DE, Harrold S, Man ST, Wang YY, Cone R, et al. Rapid transport of large polymeric nanoparticles in fresh undiluted human mucus. Proc Natl Acad Sci U S A 2007; 104:1482-1487.

66. Donadoni C, Bisighini C, Scotti L, Diomede L, Ngyen M, Nouhin J, et al. Setting of methods for analysis of mucosal antibodies in seminal and vaginal fluids of HIV seropositive subjects from Cambodian and Italian cohorts. PLOS One 2010; 5:e9920.

67. Saltzman WM, Radomsky ML, Whaley KJ, Cone RA. Antibody diffusion in human cervical mucus. Biophys / 1994; 66:508515.

68. Vidarsson G, Dekkers G, Rispens T. IgG subclasses and allotypes: from structure to effector functions. Front Immunol 2014; 5:520.

69. Yates NL, Lucas JT, Nolen TL, Vandergrift NA, Soderberg KA, Seaton KE, et al. Multiple HIV-1-specific IgG3 responses decline during acute HIV-1: implications for detection of incident HIV infection. AIDS 2011; 25:2089-2097.

70. Li Q, Zeng M, Duan L, Voss JE, Smith AJ, Pambuccian S, et al. Live simian immunodeficiency virus vaccine correlate of protection: local antibody production and concentration on the path of virus entry. J Immunol 2014; 193:3113-3125.

71. Bomsel M, Tudor D, Drillet AS, Alfsen A, Ganor Y, Roger MG, et al. Immunization with HIV-1 gp41 subunit virosomes induces mucosal antibodies protecting nonhuman primates against vaginal SHIV challenges. Immunity 2011; 34:269-280.

72. Pavot V, Rochereau N, Lawrence P, Girard MP, Genin C, Verrier $B$, et al. Recent progress in HIV vaccines inducing mucosal immune responses. AIDS 2014; 28:1701-1718. 